\title{
Rete Mirable - the marvellous network
}

\author{
DWIGHT PARKINSON
}

SUMMARY: The anastomotic channels found about the base of the brain in the presence of internal carotid inadequacy are not properly termed a rete mirable.

RESUME: Les canaux anastomotiques découverts près de la base du cerveau, en cas d'insuffisance de la carotide interne, ne constituent pas, à proprement parler, un "rete mirable".
From the Department of Neurosurgery, Faculty of Medicine, University of Manitoba.

Reprint address: Dr. D. Parkinson, $418 \cdot 404$ Graham Ave., Winnipeg, R3C 0L6 Canada.
Dorlan's Medical Dictionary (1965) defines a rete mirable as the division of a vessel into branches which then reunite to form a continuation of the original vessel. (Fig. 2.) The branching takes place without formation of capillaries and hence without loss of any of the original vessel volume. Marvellous microscopic networks exist in the vascular and nervous system throughout the human body as stated by Schulander (1957). The term "rete mirable" was assigned by Galen, (Margotta 1968) to a particularly miraculous arterial network that he recognized in lower animals without the use of a microscope. He found the carotid in the parasellar region subdividing and then, without dispersion, regathering into a continuation of the same artery. Galen found this in calves and assumed its presence in man, at the same time assigning a physiological function to the structure. It remained for Vesalius, as quoted in Garrison's (1966) book to correct the error, pointing out that a rete mirable does not exist in the carotid of humans. The closest resemblance in humans occurs in the arterioles supplying the glomeruli of the kidneys, but here a loss of fluids and electrolytes takes place before the subdivisions regroup into a continuation of the original artery. The presence of the rete mirable in the carotid of lower animals and its absence in humans implies that it serves some definite function in the lower animals because nature does nothing in vain. The nature of this function is unknown although it has been postulated by Taylor (1969) that it might serve as a cooling mechanism about the sella turcica. He states the largest of the lower animals known to have a carotid rete mirable are the eland and the oryx, both native to the hot dry climates. (Figs. 1 and 2) The rete mirable courses through a plexus of venous channels, drawn by Taylor (1969) as a venous rete mirable, in the parasellar region, a region which would be considered the cavernous sinus in humans. Carey, (1973) states that warm blooded fish have an arterial network running parallel to and intermingled with a similar mass of fine veins carrying warm oxygendepleted blood from the tissues back to the gills. The placenta of some lower animals have a similar vascular arrangement according to Schulander (1957), but again there is provision for exchanging fluid and electrolytes.

Jones (1970) and Nishimoto (1968) have used this term in neurosurgical literature to describe intracranial arterial anastomosis, particularly about the base of the brain and until deGutierrez-Mahoney and Schacter's paper, (1972) the use of the term had not been questioned.

The appearance of rich anastomosis at the site of arterial inadequacy is nothing new. With coarctation of the aorta, the intercostal arteries above and below enlarge to facilitate the collateral flow, but the intercostals do not develop as new branches from the wall of the aorta nor is there any evidence that the aorta develops any other branches de novo from its walls or back into its walls as the result of a stenosis. The intercostals, in addition to serving as collaterals, also serve their normal function of nourishing adjacent tissue. Thus, in the anastomosis there is some loss of volume whereas in a rete mirable there is no loss of volume as the vessels reconstitute into a single channel. The development of widespread anastomotic channels about a congenital absence or a congenital smallness of a vessel is in no way different. The channels are pre-existing vessels which enlarge. Humans have virtually no end-arteries, hence 

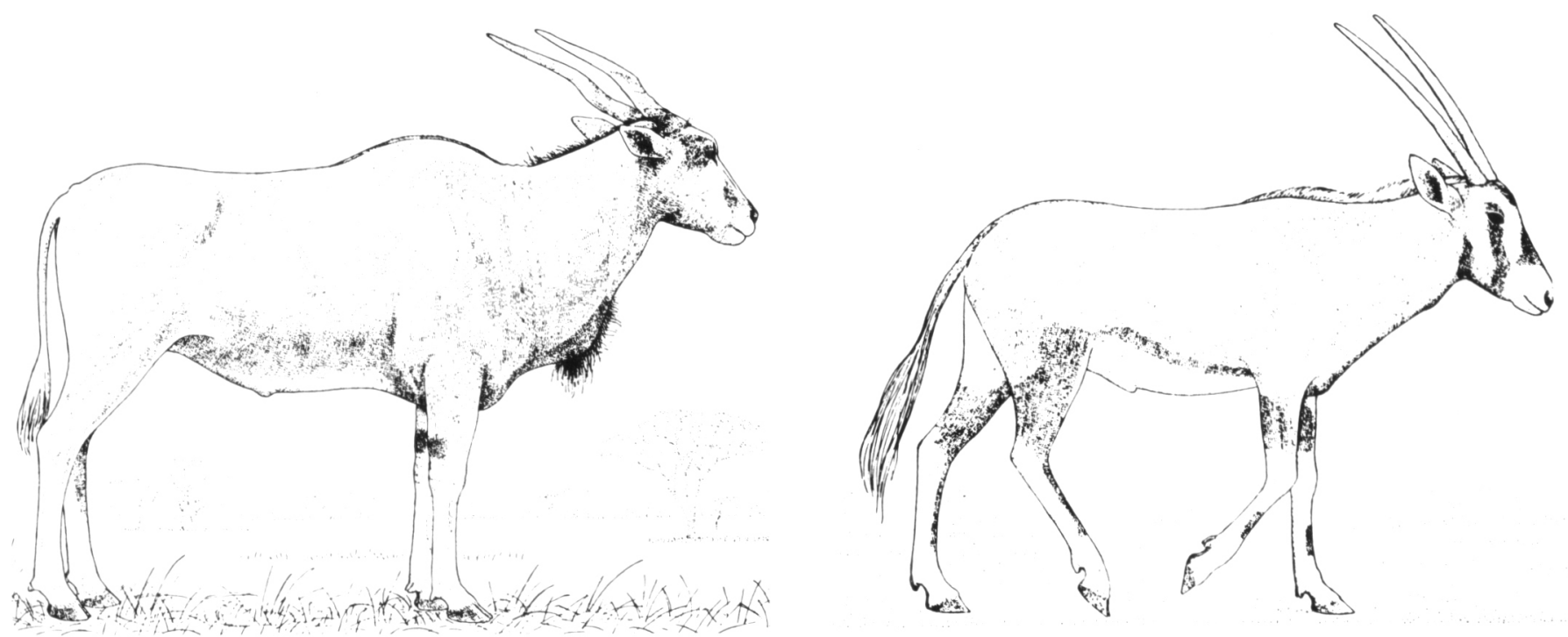

Figure 1. Drawings of the eland and the oryx, largest known animals to have a rete mirable. (Reproduced with the permission of Scientific American 220: 88. 1969. Taylor C. R.)

any artery may establish a connection to any other artery without going back to the aorta. Our (Parkinson 1964) previous work has shown that very extensive anastomosis may develop between the internal carotids or between the internal and external carotids in the parasellar region, but these again are enlargements of pre-

existing channels, which also have a nutrient function.

The angiograms of Jones and Weitzel (1970) demonstrate widespread anastomosis, but there is nothing to justify the assumption that a rete mirable has developed. An area of vascular deficiency distal to a thrombosis of the internal carotid

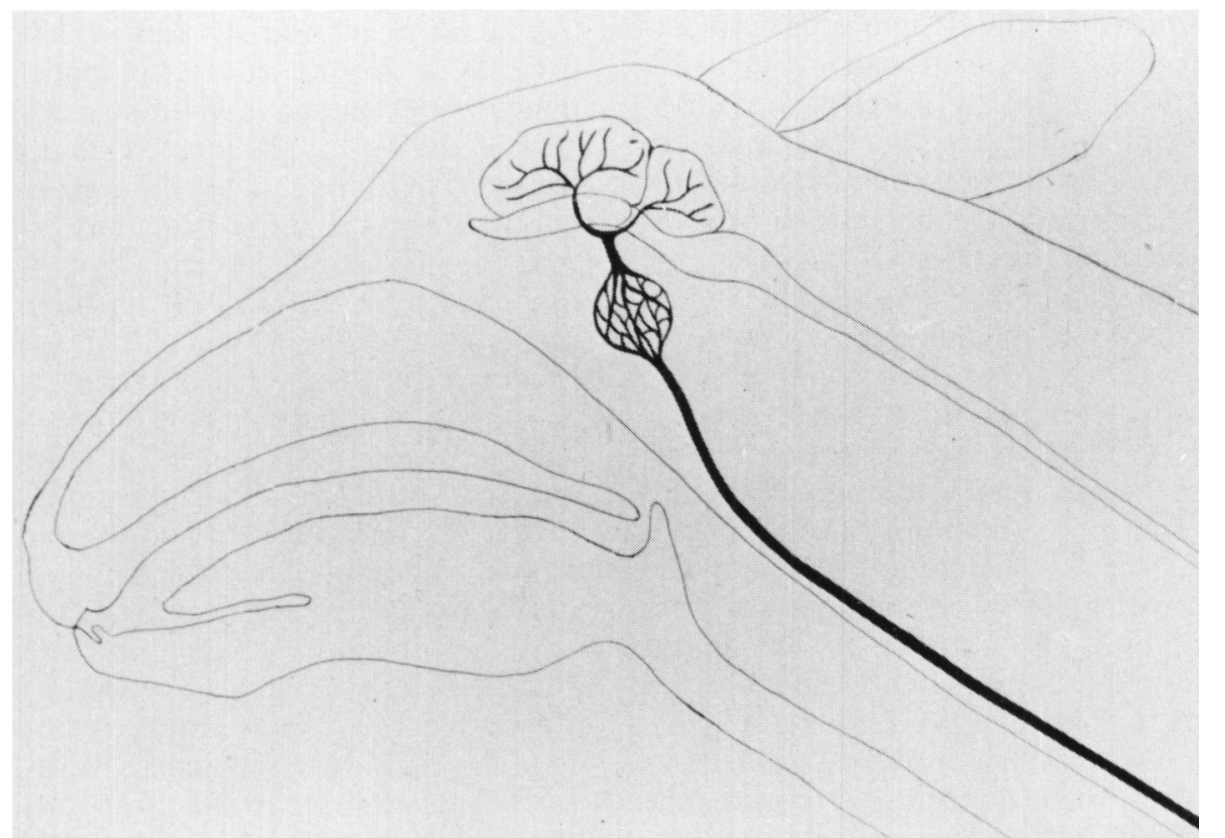

Figure 2. The dispersion of the carotid in the parasellar region into a rete mirable and its recollection into a continuation of the carotid to supply the brain as found by Taylor in the "Eland and the Oryx." (Re-drawn with the permission of Scientific American. 220: 88. 1969. Taylor, C. R.) may be well served by connections of the ophthalmic artery, meningeal branches, etcetera. All are enlargements of pre-existing normal channels, which also nourish tissue en route to their supplemental anastomotic function. The difficulty is not in explaining the etiology of this condition as stated by Jones and Weitzel (1970), but rather in trying to justify the use of the term. Nishimoto and co-workers (1969) note the "malformation" limited primarily to the distribution of the internal carotid arteries. However, they acknowledge that while the term (rete mirable) has some descriptive value it is probably not entirely appropriate.

The implication in these articles is that a rete mirable forms because of the inadequacy of the usual channels of arterial supply. With a congenitally narrow vessel, a rete mirable would be no advantage to the patient as it would not bring additional arterial blood to the region. A rete mirable would merely disperse and recollect the same inadequate volume. Nothing in our knowledge of anatomy, physiology or pathology has provided an example elsewhere in the human body of a rete mirable formed to deal with a vascular occlusion, vessel absence or congenital vessel narrowing. It is universally recognized that pre-existing connections will progressively enlarge in such a 
situation and it is also recognized that these pre-existing channels, in addition to transporting blood past a region of inadequacy also dispense branches which subdivide to capillary size and nourish the adjacent tissue.

Inasmuch as the term "rete" is a perfectly good descriptive word, and the word "anastomosis" is a perfectly good descriptive word, it seems unwarranted to exchange either or both for the equally good descriptive phrase "rete mirable" especially as the latter is the only term currently available to describe the situation in which an artery subdivides and reassembles without any loss of volume. We would therefore plead that this beautifully descriptive term be preserved with its original meaning and not be applied to the human carotid unless it can be demonstrated that such a condition actually exists.

\section{ACKNOWLEDGEMENT}

The Author is grateful to Dr. C. R. Taylor and to the Editors of Scientific American for permission to use their drawings.

\section{BIBLIOGRAPHY}

CAREY, F. G. (1973). Fishes with warm bodies. Scientific American, 228, 36-38.

DORLAN'S MEDICAL DICTIONARY (1965). W. B. Saunders and Company, Philadelphia and London, page 1313.

GARRISON, F. H. (1966). History of Medicine, W. B. Saunders and Company. Philadelphia and London. 4th Edition. Page 219 (Vesalius) page 525 (nerve net).
deGUTIERREZ-MAHONEY, C. G., and SCHACTER, M. H. (1972). The myth of the rete mirable in man. Neuroradiology, 4 , 141-158.

JONES, R. R., WEITZEL, N. (1970). Bilateral carotid vertebro-basilar rete mirable. Journal of Neurosurgery, 33, 581-586.

MARGOTTA, R. (1968). An Illustrated History of Medicine. Lewis, Paul (Ed) Hamlin Publishing Group, 42 the Centre, Feltham, Middlesex, page 96.

NISHIMOTO, A., TAKEUCHIA, S. (1968). Abnormal cerebrovascular network related to the internal carotid artery. Journal of neurosurgery, 29, 256-260.

PARKINSON, D. (1964). Collateral circulation of cavernous carotid artery; Anatomy. Canadian Journal of Surgery, 7: 251-268.

SCHULANDER, P. F. (1957). The wonderful net. Scientific American. 96, 97-107.

TAYLOR, C. R. (1969). The eland and the oryx. Scientific American. 220, 88-95. 